\begin{tabular}{|l|l|l|}
\hline \multicolumn{2}{|c|}{ PublisherInfo } \\
\hline \hline PublisherName & $:$ & BioMed Central \\
\hline \hline PublisherLocation & $:$ & London \\
\hline \hline PublisherImprintName & $:$ & BioMed Central \\
\hline \hline
\end{tabular}

\title{
Perlecan is essential for cartilage development
}

\begin{tabular}{||l|l|l||}
\hline \multicolumn{2}{|c||}{ ArticleInfo } \\
\hline \hline ArticleID & $:$ & 219 \\
\hline \hline ArticleDOI & $:$ & $10.1186 /$ ar-1999-66765 \\
\hline \hline ArticleCitationID & $:$ & 66765 \\
\hline \hline ArticleSequenceNumber & $:$ & 176 \\
\hline \hline ArticleCategory & $:$ & Paper Report \\
\hline ArticleFirstPage & $:$ & 1 \\
\hline \hline ArticleLastPage & $:$ & 4 \\
\hline \hline & & RegistrationDate : 1999-12-21 \\
ArticleHistory & $:$ & OnlineDate $:$ 1999-12-21 \\
\hline \hline ArticleCopyright & $:$ & Current Science Ltd1999 \\
\hline \hline ArticleGrants & $:$ & \\
\hline \hline ArticleContext & $:$ & 130753311 \\
\hline \hline
\end{tabular}




\section{Keywords}

Growth plate, knockout mouse, perlecan, skeletal development

\section{Context}

Perlecan is a large heparan sulphate proteoglycan with a core protein of $400-450 \mathrm{kDa}$. It is a major component of basement membranes and is also found in developing and mature cartilage, but its physiological function remains unknown. In vitro, the heparan sulphate chains of perlecan bind collagen type IV and laminin-1, structural components of the basement membrane. They also bind basic fibroblast growth factor (FGF)-2 and promote the angiogenic and mitogenic properties of this growth factor. The core protein itself binds FGF-7, fibronectin, heparin, laminin-1, platelet derived growth factor (PDGF) and ?1 and ?3 integrins. Perlecan expression is raised during organogenesis of various tissues, including cartilage, and has recently been shown to support chondrocyte differentiation (French et al 1999, J Cell Biol

145:1103-15). The development of perlecan knockout mice has demonstrated that this proteoglycan plays an important role in skeletal development as well as in maintaining the integrity of basement membranes. To determine the phenotype of perlecan knockout (Hspg2-/-) mice.

\section{Significant findings}

Neither perlecan mRNA nor protein was detected in $H s p g 2-/$ - mice. Approximately $40 \%$ of the Hspg2-/- mice died at embryonic day (E)10.5 showing abnormal cephalic development. Of the remaining $60 \%$ (survivors eventually died at birth due to respiratory failure), most showed no abnormal features until E14.5, when these mice showed progressive abnormalities in skeletal development, including short snout and mandible, cleft palate, a large domed skull with dilation of sutures, shortening of vertebral bodies with increased width and shorter but broader limbs.

At the cellular level, the growth plate of the proximal tibia of Hspg2-/- mice was completely disorganised. No distinct prehypertrophic zone was evident as assessed by in situ hybridisation of Indian hedgehog and there was no columnar organisation of hypertrophic chondrocytes, consistent with sparse and disorganised expression of type $X$ collagen mRNA and protein. Fibrous invasion with ectopic ossification from the perichondrium was also noted, together with expression of type I collagen mRNA at these sites. Collagen type II mRNA expression was decreased in the growth plate but was normal in 
the resting zone. At the protein level however, type II collagen was relatively normal although aggrecan protein was decreased.

In the growth plate of wild type mice, perlecan itself was expressed in prehypertrophic and hypertrophic zones in both the territorial and pericellular matrix. No immunostaining for perlecan was detected in Hspg2-/- mice. FGFR3 mRNA colocalised with perlecan expression in wild type mice and, although mRNA expression of this receptor was disorganised and sparse in Hspg2-/-mice, more intense immunostaining was observed relative to that for the wild type mice. This was also the case for immunolocalisation of FGF-1.

\section{Comments}

The role of perlecan in cartilage biology has not been extensively studied. Although this proteoglycan clearly plays important roles in the development and integrity of basement membranes in cardiac and neuronal tissues, its role in the maintenance of the integrity of the cartilage matrix during skeletal development clearly warrants further study. It would be interesting to know whether perlecan has any role in maintenance of normal articular cartilage and whether changes in the expression of this gene might contribute to the pathological changes observed in articular cartilage in arthritis.

\section{Methods}

Exon 7 of the perlecan gene (Hspg2) was disrupted by insertion of PGK-neomycin resistance cassette. Homozygous mutant mice were genotyped by PCR and Southern blot. Lack of perlecan expression was

verified by northern blot and immunoprecipitation of perlecan from cells labelled with $\left[{ }^{35} \mathrm{~S}\right]$. Bone and cartilage was stained with Alizarin red/Alcian blue. In situhybridisation (collagens I, II and X, Indian hedgehog, FGFR3) and immunohistochemistry (aggrecan, collagens II and X, perlecan, FGFR3 and FGF-1) were carried out on paraffin sections of embryos. Some samples were processed for electron microscopy.

\section{Additional information}

Concurrent with the publication of this paper, Costell et al also reported on the phenotype of the perlecan knockout mouse ( $\mathrm{J}$ Cell Biol 1999, 147:1109-1122). The authors provide a detailed analysis of effects on skeletal, cardiac and neuronal tissues. Skeletal defects of mice which survived to birth were very similar to those observed by Arikawa-Hirasawa et al, as were the effects on cephalic development. A higher percentage (approximately 80\%) of homozygous perlecan knockout mice died between E10.5 
and E12.5, which was attributed in this case to insufficient cardiac function. Structural defects in the basement membranes of the myocardium were observed by ultrastructural analysis.

In the same issue of the Journal of Cell Biology, Olsen writes a useful minireview ("Life without perlecan has its problems") on the possible physiological functions of perlecan and on the phenotype of the knockout mouse.

\section{References}

1. Arikawa-Hirasawa E, Watanabe H, Takami H, Hassell JR, Yamada Y: Perlecan is essential for cartilage and cephalic development. Nat Genet. 1999, 23: 354-358.

This PDF file was created after publication. 